ORIGINAL ARTICLE

\title{
A case-crossover study of transient risk factors for occupational acute hand injury
}

\author{
G S Sorock, D A Lombardi, R Hauser, E A Eisen, R F Herrick, M A Mittleman
}

Occup Environ Med 2004;61:305-311. doi: 10.1136/oem.2002.004028

See end of article for authors' affiliations

Correspondence to:

Dr D A Lombardi, Liberty

Mutual Research Institute

for Safety, 71 Frankland

Road, Hopkinton,

MA 01748, USA

david.lombardi

@libertymutual.com

Accepted 6 June 2003

Background: Workers with acute hand injuries account for over 1000000 emergency department visits annually in the United States.

Aims: To determine potential transient risk factors for occupational acute hand injury.

Methods: Subjects were recruited from 23 occupational health clinics in five northeastern states in the USA. In a telephone interview, subjects were asked to report the occurrence of seven potential risk factors within a 90-minute time period before an acute hand injury. Each case also provided control information on exposures during the month before the injury. The self-matched feature of the study design controlled for stable between-person confounders.

Results: A total of 1166 subjects were interviewed (891 men, 275 women), with a mean age (SD) of 37.2 years (1 1.4). The median time interval between injury and interview was 1.3 days. Sixty three per cent of subjects had a laceration. The relative risk of a hand injury was increased when working with equipment, tools, or work pieces not performing as expected (11.0,95\% $\mathrm{Cl} 9.4$ to 12.8), or when using a different work method to do a task $(10.5,95 \% \mathrm{Cl} 8.7$ to 12.7). Other transient factors in decreasing order of relative risk were doing an unusual task, being distracted, and being rushed. Wearing gloves reduced the relative risk by $60 \%(0.4,95 \% \mathrm{Cl} 0.3$ to 0.5$)$. Occupational category, job experience, and safety training were found to alter several of these effects.

Conclusion: The results suggest the importance of these transient, potentially modifiable factors in the aetiology of acute hand injury at work. Attempts to modify these exposures by various strategies may reduce the incidence of acute hand injury at work.

$\mathrm{T}$ he sudden transfer of energy from the work environment to susceptible human tissue characterises acute traumatic occupational injury. ${ }^{12}$ When work tasks are performed repeatedly, why does an injury occur at one point in time and not at earlier or later times? Does some set of unusual conditions in the work environment and in the individual act to increase or decrease the short term risk of an injury? These questions drive the search for transient (changing) factors that may trigger or protect against the occurrence of acute traumatic work injury. ${ }^{3}$ Few studies have documented the role of work environment or individual characteristics that may transiently increase or decrease the risk of acute traumatic injury in the workplace.

The hand is the leading body part injured at work and treated in hospital emergency departments, affecting an estimated 1080000 workers annually in the United States. ${ }^{5}$ When cuts and lacerations of the fingers and hands are combined, the number of days-away-from work cases (approximately 110000 annually), are second only to back strain and sprain frequency according to US Bureau of Labor Statistics data. ${ }^{6}$ A recent literature review of occupational acute traumatic hand injury reported that occupational hand injury rates from four US and eight international industry specific studies varied from 0.33 to 11.0 per 100 workeryears. ${ }^{7}$ Rates were highest in steel manufacturing in Singapore $(11.0),{ }^{8}$ petrochemical manufacturing in the USA $(8.2),{ }^{9}$ and the textile industry in India (6.8). ${ }^{10}$ Despite these impacts on workers and their productivity, we found only one case-control study of risk factors for hand injury in the literature. ${ }^{11}$ In that study, 124 cases of occupational hand injury were pair matched to non-injured workers by age and job type. Significantly increased risks of hand injury were associated with the use of defective equipment and doing an unusual task. Glove use decreased the hand injury risk. Expansion of traditional epidemiological designs to include the identification of transient risk factors for occupational injury have been proposed. ${ }^{12}$

In this study, we used a case-crossover design to quantify the associations between seven potential transient risk factors and the occurrence of hand injury at work. The case-crossover design uses self-matching to control for potential confounding by differences between individuals that remain stable within an individual over relatively short periods of time such as age, gender, handedness, occupation, job experience, and safety training. The design is best suited for the identification of transient risk factors for sudden onset events. ${ }^{4}$ In this study, we focused on transient exposures in the work environment in three domains: work equipment, work practices, and worker related factors. We also examined the impact of occupational category, job experience, and safety training on the associations between the transient exposures in the work environment and the risk of acute traumatic hand injury at work.

\section{MATERIALS AND METHODS}

\section{Study population}

Subjects were recruited over a three year period (1997 to 2000) from 23 occupational health clinics in five New England states: Massachusetts, Connecticut, Rhode Island, Vermont, and Maine. Further details of the study methods are provided in an earlier publication. ${ }^{13}$

To be eligible for the study, subjects must have had one or more of the following types of injury to the fingers, hand, or wrist while at work: laceration, crush, avulsion, puncture, fracture, contusion, amputation, or dislocation. After subjects were asked to give their written informed consent for a telephone interview, a clinician verified the date, time, and type of injuries and completed a case information form. Both forms were faxed to the data coordinating centre, and given to interviewers who conducted the telephone interviews in 


\section{Main messages}

- Transient work equipment, work practices, and worker characteristics were found to significantly increase the relative risk of an acute occupational injury to the hand.

- Glove use was associated with a $60 \%$ reduction $195 \%$ $\mathrm{Cl} 50-70 \%$ ) in the relative risk of a hand injury.

- Transient risk factors were associated with hand injury within strata of occupational category, years of job experience, and among those with and without safety training.

the evening, outside of the work or clinic environment. Of 1522 subjects eligible for an interview, 1179 (77.5\%) completed the interview using a structured questionnaire. Thirteen subjects were excluded from further analysis due to poor quality of responses or not meeting the case definition. Therefore, 1166 subjects were evaluated in the study. The median and mean intervals between injury and interview were 1.3 and 2.0 days respectively; $10 \%$ of subjects were interviewed five or more days after the injury date. The study was approved by the Liberty Mutual Research Institute for Safety Institutional Review Committee and the Harvard School of Public Health Human Subjects Committee.

\section{Exposure information at the time of the injury}

Questions were asked about exposures to specific transient factors during the 90 minute time period before the injury and the answers were recorded on a work-time-before-injury $\log$ by the interviewer. The seven transient factors studied were: using a machine, tool, or work material that performed differently than usual; wearing gloves; performing an unusual task; doing a task using an unusual work method; being distracted or rushed; and feeling ill. Unusual performing equipment/materials included a jammed machine, malfunctioning hand tool, a recently sharpened knife, or a work piece that was easier or harder to cut than usual. If the subject responded positively to being exposed to any transient factor, he or she was asked when the exposure occurred during the 90 minutes of work time. Subjects who reported an exposure simultaneous with the time of the injury were considered exposed in the analysis. Subjects were also asked why they were rushing or were distracted at the time of the injury, and what they thought caused the injury.

\section{Exposure information during control time}

Each subject was asked to estimate their average frequency and duration of exposure to each of seven transient factors in the past work-month. The average frequency was multiplied by the average duration of exposure to estimate the number of exposed hours per month of work time. For example, if a subject reported rushing three times a week, for 2 hours on average, given 4.3 weeks in a month, the total estimated time exposed to rushing per month for this subject would be $3 \times 2 \times 4.3$ or 25.8 hours per month. For each transient exposure, unexposed work time was determined by subtracting the amount of exposed work time in a month from the total amount of time that each subject reported working including overtime. The test-retest reliability of the questionnaire was evaluated in 29 subjects who were reinterviewed up to four days after the initial interview and asked again about the estimated number of hours of exposure during the past month. ${ }^{14}$ The reliability of recalled number of hours of exposure in the past month was high for six of seven transient risk factors (intra-class coefficients ranging from 0.84 to 0.99$)$; reliability was lower for being distracted $(\mathrm{ICC}=0.55)$. Appendix A includes the questions

\section{Policy implications}

- Intervention trials to modify these exposures by various strategies may reduce the incidence of acute hand injury at work.

we used to assess rushing in the 90 minutes before the injury and during the control time.

\section{Statistical analysis}

The analysis of case-crossover studies follows standard methods for stratified analyses. ${ }^{15} 16$ In the case-crossover design, the individual subject is the stratifying variable. We estimated the relative risk and 95\% confidence intervals for these highly stratified data using the Mantel-Haenszel estimator for person-time data. ${ }^{17}$ Relative risk estimates are based on the ratio of the observed frequency of exposure to each transient factor at the time of the injury to the expected frequency of exposure in the past work-month. Appendix B includes the relative risk calculation for five hypothetical subjects for a single exposure and the 95\% confidence interval for the point estimate. The past work-month before the injury is the control-time period selected for this analysis. ${ }^{13}$ The average incidence rate ratio (relative risk) refers to the rate of having a sudden onset hand injury when exposed to each potential transient risk factor compared to the rate when unexposed. This estimate is unbiased for follow up studies with sparse person-time data. ${ }^{18}$ Because the time interval under study is very short, the incidence rate ratio can be interpreted as the short term risk of a sudden onset hand injury. $\chi^{2}$ tests of homogeneity were used to evaluate changes in relative risk estimates across strata of potential effect modifiers. ${ }^{17}$

Potential effect modifiers presented in this study were occupational category, job experience, and safety training. We grouped the occupational categories into four classes based on similarity of work conditions and for adequate study power. Job experience was less than 1 year, $1-3$, and more than 3 years. Safety training was either "yes" or "no" on the job being done when injured.

\section{RESULTS}

Table 1 shows characteristics of the study subjects. The mean age (SD) was 37 (11.4) years. Most subjects were male (76\%), white non-Hispanic (77\%), worked in machine or assembly trades in the manufacturing industry $(42 \%)$, and had more than three years of job experience $(46 \%)$. Forty two per cent of subjects had safety training on the task they were working on when injured. The most common injury was a laceration $(63 \%)$, followed by crush injury (13\%), avulsion (8\%), puncture $(6 \%)$, fracture $(5 \%)$, contusion $(1 \%)$, and dislocation $(0.1 \%)$. Nearly all injuries were of minor severity, although $1 \%$ had a finger amputation. ${ }^{19}$

After taking into account the number of hours worked for each subject individually, the percentage of total person-time exposed in the month prior to the injury varied considerably, from $27.9 \%$ for wearing gloves to $1.1 \%$ of the time doing a task using a different method than usual (fig 1). Workers were more likely to be using unusual performing equipment/ materials, using a different work method to do a task, doing an unusual task, being distracted, rushed, or feeling ill, and were less likely to be wearing gloves at the time of their injury compared with the average amount of time they were exposed in the past month.

Of the 1166 total study subjects, 731 (63\%) reported one or more transient exposures, whereas 435 (37\%) reported no transient exposures at the time of the injury. The 731 exposed subjects reported a total of 1113 exposures or an average of 


\begin{tabular}{|c|c|c|}
\hline \multirow{4}{*}{$\begin{array}{l}\text { Characteristics } \\
\text { Age, years } \\
\text { Mean (SD) } \\
\text { Median (range) }\end{array}$} & \multicolumn{2}{|c|}{ Value } \\
\hline & \multirow{3}{*}{\multicolumn{2}{|c|}{$\begin{array}{l}37.2(11.4) \\
36(18-77)\end{array}$}} \\
\hline & & \\
\hline & & \\
\hline & No. & (\%) \\
\hline \multicolumn{3}{|l|}{ Gender } \\
\hline Male & 891 & (76) \\
\hline Female & 275 & (24) \\
\hline \multicolumn{3}{|l|}{ Race/ethnicity* } \\
\hline White/non-Hispanic & 722 & (77) \\
\hline Hispanic & 113 & (12) \\
\hline Black/non-Hispanic & 59 & (6) \\
\hline Other & 40 & (4) \\
\hline \multicolumn{3}{|l|}{ Occupational category } \\
\hline Machine trades/assembly & 486 & (42) \\
\hline Service, prof., managerial & 329 & (28) \\
\hline Packaging, MMH†, misc. & 179 & (15) \\
\hline Construction trades & 172 & (15) \\
\hline \multicolumn{3}{|l|}{ Job experience } \\
\hline$<1$ year & 304 & (26) \\
\hline $1-3$ years & 303 & (26) \\
\hline$>3$ years & 540 & (46) \\
\hline \multicolumn{3}{|l|}{ Safety training on task ${ }^{*} \ddagger$} \\
\hline Yes & 387 & (42) \\
\hline No & 537 & (58) \\
\hline \multicolumn{3}{|l|}{ Safety officer on site* } \\
\hline Yes & 563 & (60) \\
\hline No & 303 & (32) \\
\hline \multicolumn{3}{|l|}{ Company size ${ }^{*}$} \\
\hline$<50$ & 384 & (41) \\
\hline $50-249$ & 318 & (34) \\
\hline$>250$ & 232 & (25) \\
\hline
\end{tabular}

*Totals for some of the above variables will differ from 1166 because data were gathered only during the last two years of the study, and some information was missing.

$+\mathrm{MMH}$, manual materials handling.

$\ddagger$ Training on the task performed when injured.

1.5 exposures per exposed subject. Of these 731 subjects, 443 $(61 \%)$ reported one, $288(39 \%)$ had two or more, including 208 with exactly two exposures, 70 with three, six who had four exposures, and four subjects who had five exposures. The most common co-occurring exposure was rushing, occurring in 107 of 208 cases $(51 \%)$. In descending order with other exposures, rushing occurred 29 times with glove use, 27 times with distraction, 20 times with doing an unusual task, 17 times with unusual performing equipment/tools, and 14 times when using an unusual method to do a task.

Table 2 presents exposure information and relative risks of hand injury associated with each of seven transient risk



Figure 1 Percentage of subjects exposed to each of seven transient risk factors at the time of the injury (black bars) compared to the average percentage of total person-time at work exposed to each risk factor in the month prior to the injury (white bars). For example, $14.3 \%$ of subjects were exposed to unusual performing equipment/tools or work pieces at the time of the injury (unusual perform), but subjects reported being exposed to this transient factor $2.3 \%$ of work time in the previous month.

factors. Two thirds of subjects reported having worn gloves (771/1166) or being rushed (769/1166) in the month prior to the injury. Subjects reported the highest percentage of time exposed, on average, to these two factors, $27.9 \%$ and $15.0 \%$ (fig 1). The relative risks are summarised in the next section according to work domains: work equipment, work practice, and worker related exposures.

\section{Work equipment exposures}

Two exposures were related to work equipment: using unusual performing equipment, tools, or work pieces and wearing gloves. Using unusual performing equipment was associated with the highest relative risk of hand injury of all transient risk factors studied. The average number of hours exposed to this factor in the past month was low in the study subjects ( 4.5 hours), yet this work activity was associated with an 11 -fold increase in the relative risk of a hand injury (95\% CI 9.4 to 12.8 ). Wearing gloves was found to reduce the relative risk of hand injury by $60 \%$ (95\% CI $50 \%$ to $70 \%$ ). Gloves were worn on average $27.9 \%$ of the work time in the control period, but only $19.1 \%$ of subjects (225) reported wearing gloves at the time of the injury.

Table 2 Transient exposures and relative risks of occupational acute traumatic hand injury, northeastern USA, 1997-2000

\begin{tabular}{|c|c|c|c|c|c|}
\hline \multirow[b]{2}{*}{ Exposure } & \multicolumn{5}{|c|}{ One or more exposures } \\
\hline & $\begin{array}{l}\text { No. of } \\
\text { subjects } \\
\text { exposed } \\
\text { at time } \\
\text { of injury }\end{array}$ & $\begin{array}{l}\text { Average no. } \\
\text { of hours } \\
\text { exposed in } \\
\text { month prior } \\
\text { to injury } \ddagger\end{array}$ & $\begin{array}{l}\text { No. of } \\
\text { subjects } \\
\text { exposed in } \\
\text { month prior } \\
\text { to injury }\end{array}$ & $\mathbf{R R}^{*}$ & $95 \% \mathrm{Cl}^{*}$ \\
\hline Unusual performing equip/materials & 161 & 4.5 & 276 & 11.0 & 9.4 to 12.8 \\
\hline Wearing gloves & 216 & 53.1 & 771 & 0.4 & 0.3 to 0.5 \\
\hline Different work method & 107 & 2.2 & 202 & 10.5 & 8.7 to 12.7 \\
\hline Doing an unusual task & 127 & 3.9 & 356 & 6.7 & 5.7 to 8.0 \\
\hline Being distracted & 147 & 5.6 & 558 & 5.3 & 4.6 to 6.1 \\
\hline Being rushed & 290 & 29.2 & 769 & 2.4 & 2.1 to 2.7 \\
\hline Feeling ill & 25 & 2.4 & 263 & 1.9 & 1.3 to 2.8 \\
\hline
\end{tabular}

${ }^{*} \mathrm{RR}$, relative risk; $\mathrm{Cl}$, confidence interval.

†The estimated average individual hours of exposure includes subjects who report zero hours of each exposure and takes into account individual differences in hours worked including overtime. 


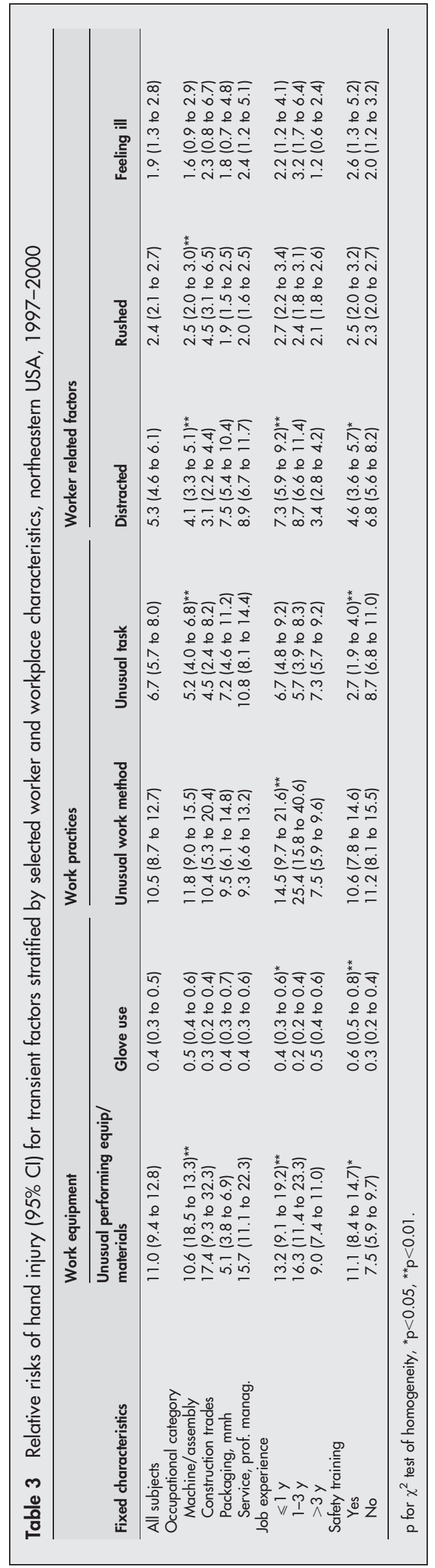

Of 161 reports of unusual performing equipment at the time of the injury, $35 \%$ were attributed to jammed machines $(n=45)$ or parts $(n=11), 27 \%$ to tools that included a very sharp knife $(n=14)$, a knife that slipped $(n=18)$, or another tool that did not perform as expected $(n=11), 15 \%$ to a work piece that was different from usual, $8 \%$ to contacting an unseen sharp edge (other than a knife), 7\% to other objects, and $8 \%$ could not be categorised.

\section{Work practice exposures}

Two exposures were considered in the work practice domain: using a different method to do a task and doing an unusual task. The former entails a change in how the usual task is done and the latter involves working on an unusual task. These exposures were associated with a 10.5-fold and 6.7-fold increase in the relative risk of injury, respectively. Both work practice transient risk factors are infrequent, occurring on average between 1 and $2 \%$ of work time (fig 1 ).

Unusual job tasks were reported by 127 subjects and included materials handling $(27 \%)$, cutting tasks $(23 \%)$, machinery maintenance, operation or un-jamming (17\%), putting a hand in an unusual place (7\%), a hammering task $(4 \%)$, other less frequent tasks $(9 \%)$, or non-classifiable ( $12 \%)$. Using an unusual method to do a task was reported by 107 subjects, and included putting a hand in an unusual position $(22 \%)$, using a different tool for the task $(21 \%)$, using high force hand movements (13\%), using an unusual work piece $(7 \%)$, using a different hand $(6 \%)$, coming too close to a blade $(5 \%)$, other unusual methods $(10 \%)$, or unclassifiable (16\%).

\section{Worker related exposures}

Being distracted $(\mathrm{RR}=5.3 ; 95 \% \mathrm{CI} 4.6$ to 6.1$)$, and to a lesser extent, being rushed ( $\mathrm{RR}=2.4 ; 95 \% \mathrm{CI} 2.1$ to 2.7 ) or feeling ill $(\mathrm{RR}=1.9 ; 95 \% \mathrm{CI} 1.3$ to 2.8$)$, were also significant risk factors for hand injury. The leading reasons for rushing $(n=255)$ were: working quickly to get the current job done to get to the next one $(23 \%)$, catching up with backed-up work $(22 \%)$, being rushed by supervisors or customers $(19 \%)$, other time pressure/emergencies (17\%), preparing to go home or other destination $(10 \%)$, or being understaffed $(8 \%)$. Distractions $(n=133)$ were due to talking or looking at a coworker (53\%), thinking about non-work tasks (losing concentration) $(30 \%)$, or other external $(13 \%)$ or internal distracters $(4 \%)$.

In addition to the structured questions on transient exposures, subjects were asked at the end of the interview what they thought led to the injury. The responses for the top $80 \%$ of "causes" were being careless (17\%), distracted (14\%), "freak" accident (12\%), rushing (10\%), unusual performing machinery or tools $(8 \%)$, unknown (5\%), hand slipped $(5 \%)$, unusual method $(5 \%)$, or related to a co-worker's actions $(4 \%)$.

\section{Effect of occupational category, job experience, and safety training}

Relative risks for the six risk factors and one protective factor were also statistically significant within each occupational category, level of job experience, and among those with and without safety training (table 3 ). Workers in packaging and manual material handling trades had the lowest relative risk associated with unusual performing equipment. Workers in the service, professional, and managerial trades had the highest relative risks associated with doing an unusual task and distraction, while rushing was associated with the largest relative risk in construction. Compared with more than three years of job experience, having less than three years was associated with larger relative risks when exposed to unusual performing equipment, using an unusual method to do a task, and being distracted. For five out of seven exposures, 
the strongest effects were in the second year of job experience. The association was stronger for unusual performing equipment among those with safety training. By contrast, safety training was associated with a lower relative risk of doing an unusual task and being distracted. Glove use was more protective in subjects without safety training.

\section{DISCUSSION}

These results suggest an important role for five transient risk factors in the aetiology of occupational acute traumatic hand injury, namely: unusual performing equipment/materials, using a different work method to do a task, doing an unusual task, being distracted, and rushing. Glove use was associated with a reduced risk of acute hand injury. The results of this study should be limited to occupational health clinic based patients with a similar spectrum of injuries and employed in similar occupational categories.

In this study, use of unusual performing work equipment/ materials such as jammed machinery was associated with the largest relative risk of a hand injury $(\mathrm{RR}=11.0,95 \% \mathrm{CI} 9.4$ to 12.8 ), as it was in an earlier case-control study (odds ratio 30.0 , $95 \%$ CI 5.0 to $\infty)$. ${ }^{11}$ This relatively rare transient risk factor ( $2.3 \%$ of the previous work-month) has been identified in injuries related to servicing equipment, where un-jamming and cleaning activities comprised $60 \%$ of the tasks associated with injuries. ${ }^{20}$ Furthermore, personnel involved in full time machinery maintenance have a disproportionate number of finger amputations at work. ${ }^{21}$ Modified machinery maintenance schedules, mandatory lockout/tagout procedures, improved training for machine operators in un-jamming procedures, improved training for workers who use knives, and glove use at high risk times are all potential interventions to reduce the risk of hand injury. ${ }^{22}$

To understand the impact of these transient risk factors on the absolute risk of workplace injury, one must consider the baseline risk of injury, the frequency of exposure to the transient risk factor and the relative risk associated with it. For example, workers in this study reported working with unusual performing equipment for $2.3 \%$ of their work-time. Assuming that the average annual risk of an acute hand injury at work is $5.0 \%$ in manufacturing industries and the relative risk associated with working with unusual performing equipment among workers in this industry is 10.6, we can estimate the absolute risk as $(0.977 \times 5 \%)+(0.023 \times$ $5 \% \times 10.6)=6.1 \%$. Thus, under these assumptions the average annual absolute excess risk associated with working with unusual performing equipment would be $1.1 \%$ in populations of workers with a similar distribution of transient exposures.

Glove use was the only personal protective equipment examined in this study. It was consistently found to reduce the relative risk of hand injury by about $60 \%$ in the presence of other transient exposures. Wearing gloves was also associated with a decreased risk of a hand injury in a casecontrol study of hand injuries in municipal employees $(\mathrm{OR}=0.38$, 95\% CI 0.14 to 0.89$) .{ }^{11}$ Gloves could be worn more often than they are reported to be worn. However, in $19 \%$ of the injuries that occurred while gloves were worn, they may not protect against the mechanical energy being transferred to the hand. Glove use appears to reduce the risk of lacerations and puncture injuries but not crush, fractures, avulsions, or amputations among the subjects in this study. ${ }^{23}$ More research is needed on reasons why gloves are or are not worn by workers doing specific tasks.

Two work practice factors (using a different method to do a task and doing an unusual task) also increased the relative risk of a hand injury. Both of these changes in work practices are relatively unusual exposures. Hand injury risk due to unfamiliarity with a task was also increased in an earlier case-control study $(\mathrm{OR}=23,95 \%$ CI 3.7 to $\infty) .{ }^{11}$
Two worker related behavioural transient factors, being distracted and rushing, were associated with hand injury. Experimental research on distraction and performance suggests that distraction effects increase as a function of task complexity and may diminish as a function of task practice. ${ }^{24}$ This is consistent with reduced effects of distraction seen for persons with greater than three years of job experience. Rushing was a common transient risk factor in this study. Twenty five per cent of subjects (290/1166) were rushing at the time of the injury (table 2 ). Machine operator speed is positively correlated $(0.76)$ with inadvertent machine initiation errors using an industrial machine simulator. ${ }^{25}$ As a result of rushing, machine operators performing repetitive tasks may lose coordinated control of their limb movements.

Occupational category, job experience, and safety training were observed to alter the effects of the transient exposures in this study (table 3 ). In the work equipment domain, the relative risk associated with unusual performing equipment was lowest in packaging and manual materials handling, where excessive forces from machinery and tool exposure are less likely than in other occupations. The relative risk was highest for unusual performing equipment in persons with less than three years of job experience; glove use was associated with the lowest relative risk of injury during two of these three years. Subjects with safety training had a higher relative risk associated with unusual performing equipment than subjects without training. This may reflect the inherent risk of jobs targeted for safety training. Without safety training, glove use had a greater protective effect, underscoring the importance of this preventive strategy in the absence of formal safety training.

With respect to work practices, using an unusual method to do a task was associated with a greater increase in the relative risk of hand injury among workers with fewer years of job experience compared to those with three or more years. This may reflect learning to do the job, as well as more experience with different methods of doing a task in persons with greater than three years of job experience. The relative risk of injury while doing an unusual task was lower in manufacturing and construction trades than other occupations due perhaps to the more restricted nature of the work tasks. However, where tasks become more variable, that is when rotating jobs or doing repair work, the risk of a hand laceration may increase and require more, not less, PPE use. ${ }^{26}$ This may be especially relevant in service, professional, and managerial occupations where persons may leave their job role to do some unusual hazardous task. The impact of safety training on doing an unusual task was highly discordant. The question as worded was whether the subject had received safety training on the task being done at the time of the injury. Because this was by definition an unusual task for the subject, safety training, if present, could have a significant effect in altering injury risk. This suggests an important role for safety training that emphasises caution across a range of unusual tasks or work conditions. Since human errors cannot be eliminated, error identification and compensatory actions, ranging from glove use at specific times to slowing down and concentrating, may need to be included in the safety training process. $^{27}$

The occurrence of some transient exposures examined in this study are not uniform by time into the work shift. ${ }^{28}$ For example, $17.7 \%$ of the 588 subjects injured in the first four hours of the shift reported unusual performing machine, tools, or materials at the time of their injury compared to $10.7 \%$ of the 393 subjects injured from 4-8 hours into their work shift. This suggests possibly more use of machine, tools, or equipment earlier into the work shift than later, or something about the equipment is more hazardous during earlier than later times. 
Distraction was the worker related factor most often modified by the fixed factors under study. Opportunities for distraction may be greater in work environments where interpersonal activity is required, such as in service occupations compared to manufacturing or construction occupations. Services and manual materials handling occupations also had a higher relative risk associated with distraction than other occupational categories which may be due to the presence of customers adding to the sources of distraction. Clearly, the relative risk associated with distraction is less with increased job experience (over three years), perhaps due to greater tenure in the manufacturing and construction occupations, or due to reduced distractibility after a job becomes routine. Safety training may include increased awareness of distractions and their avoidance or control, as seen by the lower relative risk of distraction among workers with safety training. The higher relative risk associated with rushing in construction may be due in part to the excess number of hazards and high impact forces when rushing while doing construction tasks. The effects of feeling ill was not different across categories of occupational category, job experience, and safety training due perhaps to infrequent exposure, or to the relatively minor degree of illness not prohibiting the subject from working on the day of the injury.

The major strength of this study is control by the self matched design for stable characteristics that are different between individuals such as age, experience, eye-hand coordination, reflex time, injury history, occupation, and safety training. While the design focuses on transient risk factor identification, it does not permit examination of fixed risk factors such as occupation and job experience, which are important determinants of workplace injury. Fixed risk factors can only be evaluated as effect modifiers. The major limitation of this and other retrospective research studies is recall bias. ${ }^{29}$ Subjects may have overestimated exposures close to the time of the injury. They may have also underestimated exposure in control time because of memory lapse, or difficulty in estimating exposure in the control period. This would bias the relative risks away from the null value. Furthermore, we implicitly assume that the nature of the job hazards has not changed significantly during the month prior to the injury. Unfortunately, there is no currently available gold standard for the self-reported, retrospective transient exposures in this study.

If the hazard period associated with a particular exposure is longer than that assessed, we may have underestimated the relative risk or failed to detect it. In this study, we hypothesised that the effect of the majority of the assessed exposures on the risk of hand injury would be immediate, and thus designed our questionnaire to focus on a very short interval preceding the injury. However, for the example of feeling ill, it is certainly plausible that the effect is more prolonged, either due to a direct effect of the illness or through an intermediate pathway resulting from the illness such as lack of sleep or medication use. Thus, it is possible that our study provided a conservative estimate for this exposure.

Another limitation of this study is our inability to deconfound the effects of within-subject confounding by cooccurring transient risk factors. This is because we did not ask about the co-occurrence of transient risk factors in the control period (month prior to injury) and were unable to use the control period one hour before the injury due to the long median exposure duration of four of seven exposures. ${ }^{13}$ Even if we restricted the analysis to cases with just one exposure at the time of the injury, the control periods of those subjects could still have co-occurring exposures (for example, being rushed and distracted) leading to some residual uncontrolled within-person confounding. Complex interactions may accumulate over time in relation to the acute onset of an injury that are difficult to distinguish within individuals. In the future, asking about exposures at the same time of the day on the previous workday or workdays, or by asking about rushing and other common transient exposures in the usual frequency period (one month earlier) should be investigated. Other potential transient risk factors, such as emotional upset or hangovers from alcohol intake the night before were not examined in this study and may be important exposures to explore.

In conclusion, these results suggest that five transient exposures increase the risk of a hand injury in the workplace. They are, in decreasing order of relative risk: equipment, tools, or work pieces not performing as expected; using a different work method to do a task; doing an unusual task; being distracted; and being rushed. Feeling ill was weakly associated with hand injury risk in this study. Glove use reduces hand injury risk. These results suggest that attempts to modify unusual exposures and glove use by various strategies including engineering controls, safety training, and administrative controls may reduce the incidence of acute hand injury at work.

\section{ACKNOWLEDGEMENTS}

This work was supported by the National Institute for Occupational Safety and Health, Grant No. R01 OH-03763 and the Liberty Mutual Research Institute for Safety.

We are grateful to the following occupational health clinics and clinicians for their participation in the Hand Injury Study: Occupational Health + Rehabilitation $(\mathrm{OH}+\mathrm{R})$, VP Operations, Lynne Rosen; Warwick, RI, Dana Sparhawk, Susan Booth; Boston, MA, Jay Burstein, Dianna Seufert; Sturdy Memorial Hospital, Attleboro, MA, Robert Hurley, Rosemary Turner; Pawtucket, RI, Elaine Allendorf; Wellesley, MA, John Burress; Wilmington, MA, William Patterson; South Burlington, VT, Jeffrey Allen; Essex Junction, VT, Susan Hetman; Industrial Health Care Inc., VP Operations, Susan Henry; Windsor, CT, Frank Hall; Norwich, CT, Donald Bradley, John Baitinger; East Hartford, CT, David Feinstein; Stratford, CT, Michael Saffir; Norwalk, CT, Howard Zusman; Waterbury, CT, Kenneth Johnson, Shelly Edwards; Wallingford, CT, Jennifer Patten; Morton Hospital, Taunton, MA, Edward D'Andrea; Liberty Mutual Medical Center, Somerville, MA, William Wheeler, Mary Shaughnessy; Texas Instruments, Attleboro, MA, Verda Larsson; Wyman-Gordon, Mary Freyermuth; Bangor, ME, Paul Hermann; Lewiston, ME, Gordon Caldwell; Portland, ME, Robert Myer. We appreciate the efforts of Judith Oulette, Leslie Holander, Kate Dwyer, Mary Dionne, and Susan Martin in conducting telephone interviews, and Roger Racine for his technical assistance. Drs Bradley Evanoff and Jennifer Bell provided useful comments on the manuscript. We thank Patti Boelsen for her preparation of the manuscript.

\section{Authors' affiliations}

G S Sorock, Center for Injury Research and Policy, Johns Hopkins Bloomberg School of Public Health, Baltimore, MD, USA

D A Lombardi, Liberty Mutual Research Institute for Safety, Hopkinton, MA, USA

R Hauser, E A Eisen, R F Herrick, M A Mittleman, Occupational Health Program, Department of Environmental Health, Harvard School of Public Health, Boston, MA, USA

\section{APPENDIX A}

Sample question used to assess exposure at time of injury and the expected frequency of rushing in the past week or month

"Were you rushed for any reason at the time of the injury back to 90 minutes before the injury? Were you working faster than usual?"

- If yes, "when were you rushed during the 90 minute period?"

- If yes, "what caused you to rush?" 
Table A1 Usual frequency analysis for five subjects using the Mantel-Haenszel incidence rate ratio (IRR $\left.R_{M H}\right)$ : example of exposure to rushing

\begin{tabular}{llllll}
\hline Subject no. & $\begin{array}{l}A_{1_{i}} \\
\text { exposed }\end{array}$ & $\begin{array}{l}A_{0_{i}} \\
\text { unexposed }\end{array}$ & $\begin{array}{l}T_{1_{i}} \\
\text { hours exposed }\end{array}$ & $\begin{array}{l}T_{0_{i}} \\
\text { hours unexposed }\end{array}$ & $\begin{array}{l}T_{i} \\
\text { hours total }\end{array}$ \\
\hline 1 & 1 & 0 & 1.25 & 170.75 & 172.00 \\
2 & 0 & 1 & 0.50 & 171.50 & 172.00 \\
3 & 0 & 1 & 0.05 & 154.77 & 154.82 \\
4 & 0 & 1 & 2.00 & 204.40 & 206.40 \\
5 & 0 & 1 & 20.00 & 152.00 & 172.00 \\
\hline
\end{tabular}

(Always ask) "How many times per week or month on average are you rushed at work? For what length of time on average are you rushed at work?"

\section{APPENDIX B}

Table Al shows the usual frequency analysis for five subjects using the Mantel-Haenszel incidence rate ratio (IRRMH).

The IRR $_{M H}$ is the ratio of: ${ }^{17}$

the rate of occurrence of cases in exposed subjects

the rate of occurrence of cases in non-exposed subjects

$$
I R R_{M H}=\frac{\sum_{i} A_{1_{i}} T_{0_{i}} / T_{+i}}{\sum_{i} A_{0_{i}} T_{1_{i}} / T_{+i}}
$$

Where:

- $A_{1_{i}}$ is exposure at the time of the injury $(1,0)$

- $A_{0_{i}}$ is non-exposure at the time of the injury $(1,0)$

- $T_{1_{i}}$ is amount of person-time in hours exposed in past work-month

- $T_{0_{i}}$ is amount of person-time in hours unexposed in past work month

- $T_{i}$ is total amount of time in hours at work in past work month.

$$
\begin{aligned}
& \text { Incidence rate ratio (IRR) } \\
& \begin{aligned}
\frac{1 \times 170.75}{172}+\frac{0 \times 171.5}{172}+\frac{0 \times 154.77}{154.82}+\frac{0 \times 204.4}{206.4}+\frac{0 \times 152}{172} \\
\frac{0 \times 1.25}{172}+\frac{1 \times 0.5}{172}+\frac{1 \times 0.05}{154.82}+\frac{1 \times 2}{206.4}+\frac{1 \times 20}{172} \\
=\frac{0.990}{0.129}=7.7
\end{aligned}
\end{aligned}
$$

N.B. The interpretation of the relative risk estimate is that the risk of a hand injury is 7.7 times higher when rushing than when not rushing. If subjects are never exposed or always exposed they add 0 to the numerator and denominator.

Variance estimator for the logarithm of the MantelHaenszel incidence rate ratio can be found by using the formula on page 270 of Rothman and Greenland. ${ }^{17}$ The $95 \%$ confidence interval for the above IRR estimate is 1.17 to 50.35 .

$$
\operatorname{Var}\left[\operatorname{In}\left(I R_{M H}\right)\right]=\frac{\sum_{i} M_{1_{i}} T_{1_{i}} T_{+i}}{\sum_{i} A_{0_{i}} T_{1_{i}} / T_{+i} \sum_{i} A_{0_{i}} T_{1_{i}} / T_{+i}}
$$

Where:

$M_{\mathrm{l}_{i}}=A_{\mathrm{1}_{i}}+A_{0_{i}}$ is the total number of cases in stratum $i$.

\section{REFERENCES}

1 Haddon W. Advances in the epidemiology of injuries as a basis for public policy. Pub Health Rep 1980;95:41 1-21.

2 Hagberg M, Christiani D, Courtney T, et al. Conceptual and definitional issues in occupational injury epidemiology. Am J Ind Med 1997;32:106-15.

3 Mittleman M, Maldonado G, Gerberich S, et al. Alternative approaches to analytical designs in occupational injury epidemiology. Am J Ind Med 1997:32:129-41.

4 Maclure M, Mittleman M. Should we use a case-crossover design? Annu Rev Public Health 2000;21:193-221.

5 Centers for Disease Control. Nonfatal occupational injuries and illnesses treated in hospital emergency departments - United States, 1998. MMWR 2001:50(16):313-17.

6 Courtney TK, Webster W. Disabling occupational morbidity in the United States. An alternative way of seeing the Bureau of Labor Statistics' data. $J$ Occup Environ Med 1999;41:60-9.

7 Sorock G, Lombardi D, Courtney T, et al. Epidemiology of occupational acute traumatic hand injuries: a literature review. Safety Science 2001:38:241-56.

8 Ong CN, Phoon WO, Iskander N, et al. Shiftwork and mill injuries in an iron and steel mill. Appl Ergon 1987; 18:51-6.

9 Jensen DG. Scenario analysis of finger injuries in industrial accidents. Proceedings of Human Factors Society, 31 st annual meeting, 1987:916-19.

10 Nag PK, Patel VG. Work accidents among shift workers in industry. Int $J$ Ind Ergon 1998;21:275-81.

11 Hertz R, Emmett E. Risk factors for occupational hand injury. J Occup Med 1986:28:36-41

12 National Institute for Occupational Safety and Health. National occupational research agenda. Traumatic occupational injury research needs and priorities. DHHS (NIOSH) Publication 98-134. Cincinnati, OH: US Department of Health and Human Services, Centers for Disease Control and Prevention, National Institute for Occupational Safety and Health, 1998.

13 Sorock G, Lombardi D, Hauser R, et al. A case-crossover study of occupational traumatic hand injury: methods and initial findings. Am J Ind Med 2001;39:171-9.

14 Lombardi $D$, Sorock $G$, Lesch $M$, et al. A reliability study of potential risk factors for acute traumatic occupational hand injuries. Am J Ind Med 2002;42:336-43.

15 Maclure $M$. The case-crossover design: a method for studying transient effects on the risk of acute events. Am J Epidemiol 1991;133:144-53.

16 Mittleman M, Maclure M, Robins J. Control sampling strategies for casecrossover studies: an assessment of relative efficiency. Am J Epidemio 1995; 142:91-9.

17 Rothman K, Greenland S. Modern epidemiology. 2nd edn. Philadelphia, PA: Lippincott-Raven Publishers, 1998:269-75.

18 Greenland S, Robins JM. Estimation of a common effect parameter from sparse follow-up data. Biometrics 1985;41:55-68.

19 Sorock G, Lombardi D, Hauser E, et al. Acute traumatic occupational hand injuries: type, location, and severity. J Occup Environ Med 2002;44:345-51.

20 Bureau of Labor Statistics. Injuries related to servicing equipment. Bulletin 2115. Washington, DC, 1981.

21 Sorock G, Smith E, Hall N. Hospitalized occupational finger amputations, New Jersey, 1985 and 1986. Am J Ind Med 1993;23:439-47.

22 American National Standards Institute (ANSI). Risk assessment and risk reduction - a guide to estimate, evaluate and reduce risks associated with machine tools. ANSI Technical Report B1 1.TR3-2000. Washington, DC, 2000

23 Sorock G, Lombardi D, Peng D, et al. Glove use and the relative risk of acute hand injury: a case-crossover study. J Occup Environ Hyg 2004;1:1-9.

24 Graydon J, Eysenck M. Distraction and cognitive performance. European Journal of Cognitive Psychology 1989;1:161-79.

25 Trump T, Etherton J. Machine-cycling errors with foot switches in repetitive tasks: a workstation design simulation experiment. Appl Ergon 1986:17:199-208

26 Bell JL, MacDonald LA. Hand lacerations and job design characteristics in line-paced assembly. J Occup Environ Med 2003;45:848-56.

27 Reason J. Human error. Cambridge, UK: Cambridge University Press, 1990.

28 Lombardi DA, Sorock GS, Hauser R, et al. Temporal factors and the prevalence of transient exposures at the time of an occupational traumatic hand injury. J Occup Environ Med 2003;45:832-40.

29 Sorock G, Lombardi D, Gabel C, et al. Case-crossover studies of occupational trauma: methodological caveats. Inj Prev 2001;7(suppl I):i38-42. 